
\title{
CIÊNCIA'NATURA
}

\section{Variabilidade espacial da temperatura do ar com uso de transectos móveis em Tupanciretã/RS, sob domínios atmosféricos tropicais}

\author{
Spatial variability of air temperature with mobile transects in Tupanciretã/RS, under tropical \\ atmospheric conditions
}

Cássio Arthur Wollmann ${ }^{1}$, Santhiély Láksmi Silva Gomes ${ }^{2}$ e Amanda Comassetto Iensse ${ }^{3}$

${ }^{1}$ Prof. Doutor, Departamento de Geociências, Universidade federal de Santa Maria, Santa Maria/RS, Brasil cassio_geo@yahoo.com.br

${ }^{2}$ Mestranda PPGGEO, Departamento de Geociências, Universidade federal de Santa Maria, Santa Maria/RS, Brasil

santhielygeo@gmail.com

${ }^{3}$ Geógrafa, Mestranda PPGGEO/UFSM, Departamento de Geociências, Universidade federal de Santa Maria, Santa Maria/RS, Brasil

comassettoamanda@gmail.com

\section{Resumo}

O objetivo geral desta pesquisa consistiu em analisar a distribuição espacial da temperatura do ar na área urbana de Tupanciretã/RS, sob domínios tropicais. Para a realização desta pesquisa climática in loco necessitou-se a realização de trabalho de campo com execução da metodologia de transectos móveis. Mediu-se a temperatura do ar às 15 h. Foi confeccionado mapa de variação espacial da temperatura do ar registrada no ambiente urbano e utilizou-se de cartas sinóticas, imagens de satélite e dados da rede oficial de estações meteorológicas do INMET para identificação dos sistemas atmosféricos atuantes e comparações com os dados e sua magnitude. Após análise climática e cartográfica, observou-se que as variações térmicas nesta pesquisa primária, ocorreram com média magnitude, registrando-se diferenças de até $3^{\circ} \mathrm{C}$ entre os bairros da cidade e em comparação com a área rural, que promoveu redução em até $50 \%$ das temperaturas mais elevadas registradas na parte central da cidade. Ainda, para esta cidade, a orientação de vertentes e presença de corpos hídricos foi fundamental para a diferenciação espacial da temperatura em comparação com as áreas periféricas de baixa renda, centrais e comerciais.

Palavras-chave: Variabilidade espacial; temperatura do ar; área urbana; Tupanciretã/RS; Circulação Atmosférica Regional; Domínio tropical.

\section{Abstract}

This research concerns in to analyze the spatial distribution of air temperature in the urban area of Tupanciretã / RS, under tropical domains. In order to carry out this on-site climate research, it was necessary to perform fieldwork with the execution of the mobile transect methodology. The air temperature was measured at 3:00 p.m. A map of spatial variation of air temperature recorded in the urban environment was made using synoptic charts, satellite images and data from the official network of INMET meteorological stations to identify atmospheric systems and comparisons with the data and their magnitude. After the climatic and cartographic analysis, it was observed that the thermal variations in this primary survey occurred with average magnitude, registering differences of up to $3{ }^{\circ} \mathrm{C}$ between the city's districts and in comparison with the rural area, which promoted reduction by up to $50 \%$ of the highest temperatures recorded in the central part of the city. Also, for this city, the orientation of slopes and the presence of water bodies were fundamental for the spatial differentiation of the temperature in comparison with the peripheral areas of low income, central and commercial.

Keywords: Spatial variability; air temperature; urban area; Tupanciretã/RS; Regional Atmospheric circulation; Tropical domain. 


\section{Introdução}

A sociedade está buscando cada vez mais as cidades para viverem, além do incremento à população já existente agregando funções do campo a cidade, para que haja cada vez menos a dependência do meio rural. Diversas mudanças acabam por ser ocasionadas com estas alterações na paisagem, e problemas provenientes desta ocupação muitas vezes acelerada e sem planejamento passam a existir. Com o tempo, as cidades começaram a expandir-se e aglomerar-se paulatinamente, adquirindo novas funções.

Santos (1993) coloca que no Brasil a agricultura comercial e a expansão mineral foram a base de um povoamento e uma criação de riquezas redundando na ampliação da vida de relações e no surgimento de cidades no litoral e no interior do país. A mecanização do campo ocasionou uma demanda populacional para as cidades na busca de novas oportunidades de emprego, já que a mão de obra no campo foi substituída pelas máquinas.

Nesse sentido as cidades começaram a receber novas funções, as quais atraíam cada vez mais a população excedente do meio rural, proporcionando um aumento no número de pessoas, e por consequência deste aumento, problemas começaram a surgir relacionados com a ocupação e modificação do meio natural de forma pouco ordenada. Ainda com o aumento da demanda para as cidades, a população se deparou com a falta de empregos necessários, nem a existência de bens e serviços essenciais, um empobrecimento da população e uma degradação de suas condições de existências.

No Brasil, o processo de urbanização corporativa também é um grande problema no desenvolvimento das cidades brasileiras. Santos (1993) afirma que a urbanização corporativa é empreendida sob o comando dos interesses das grandes firmas, constitui um receptáculo das consequências de uma expansão capitalista devorante dos recursos públicos, uma vez que estes são orientados para os investimentos econômicos, em detrimento dos gastos sociais.

Nesse sentido, os problemas climáticos são mais perceptíveis pelas pessoas que habitam a cidade, e que são sentidos no dia a dia da sociedade. Para Mendonça (1994) o clima urbano é o resultado das interações no ambiente natural, tais como a retirada da cobertura vegetal, modificação nas formas de relevo e na rugosidade da superfície, concentração de edificações, equipamentos e pessoas, impermeabilização do solo, canalização do escoamento superficial, acumulação de partículas e gases na atmosfera e produção de energia artificial.

A diferença do clima entre as cidades e o campo já eram mostradas nos primeiros registros meteorológicos, e então, comentadas no pioneiro estudo do clima de uma cidade, feito por Howard (1833) em Londres. Este estudo passou a ser referência, e é tratado em diversas monografias que tratam do tema, e expandiu-se a literatura incluindo estudos sobre a influência dos povoados e da indústria no clima

Nesse contexto, o objetivo desta pesquisa foi o de analisar a distribuição espacial da temperatura do ar na área urbana de Tupanciretã/RS, às 15 horas, em condições de domínio polar continental.

\section{Localização da área de estudo}

A área urbana do município de Tupanciretã/RS dista 415quilômetros de Porto Alegre e está localizada entre as coordenadas $29^{\circ} 04^{\prime} 50^{\prime \prime}$ Sul e a uma longitude $53^{\circ} 50^{\prime} 09^{\prime \prime}$ Oeste, com uma população segundo estimativa do Instituto Brasileiro de Geografia e Estatística (IBGE, 2017), em 23.805 habitantes, e destes, mais de $60 \%$ habitam no meio urbano. Nesta região, que é limite da faixa de fronteira internacional, conforme a Lei
6.634/1979 (Figura 01), desenvolvem-se principalmente atividades agrícolas (cultivo de soja, milho e trigo) e agropecuária extensiva. Tupanciretã é considerada a capital da soja, devido à sua produção, e sua área municipal é de $2.252 \mathrm{~km}^{2}$, e uma altitude média de 400 metros acima do nível do mar.

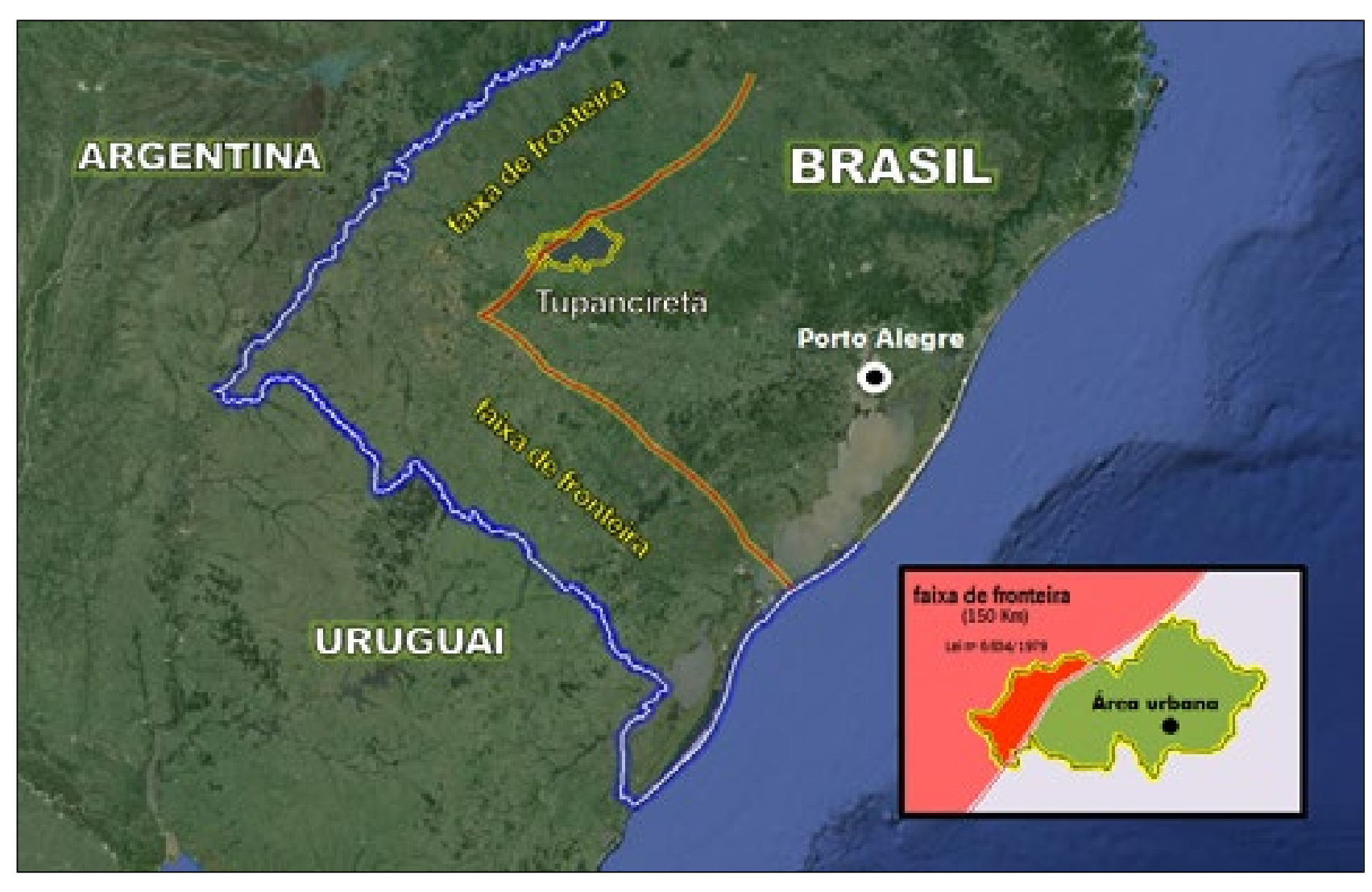

Figura 01 - Localização do município de Tupanciretã e sua área urbana

Fonte: http://eduardoaugusto-irib.blogspot.com.br/

O estado do Rio Grande do Sul apresenta clima subtropical, no qual Tupanciretã faz parte da Zona Subtropical, possuindo um clima Mesotérmico brando superúmido sem seca, apresentando chuvas bem distribuídas ao longo do ano. (SARTORI, 1993), com totais médios de precipitação em torno de $1916 \mathrm{~mm}$ a $1971 \mathrm{mmm}$ (BARATTO, 2017).

Segundo a SEPLAG (2006), o município de situa-se nos Planaltos e Chapadas da Bacia do Paraná, que é composta por uma sequência de derrames de rochas vulcânicas pertencentes a Formação Serra Geral Tupanciretã possui um destaque no seu quadro natural, especialmente no que tange a hidrografia e a biogeografia. O município se localiza nos divisores de água de quatro grandes bacia hidrográficas estaduais: Alto Jacuí, Ibicuí, Ijuí e Butuí-Piratinim-Icamaquã (SEMA, 2009).

Em especial a bacia hidrográfica do Alto Jacuí, onde se insere a área urbana de Tupanciretã, bem como a porção leste do município, esta é dominada pelo Bioma Pampa. Sendo assim, em relação ao Alto Jacuí, esta é a única área da bacia com domínio pampeano, ressaltando a importância da pesquisa de clima urbano neste bioma (Figura 02). 


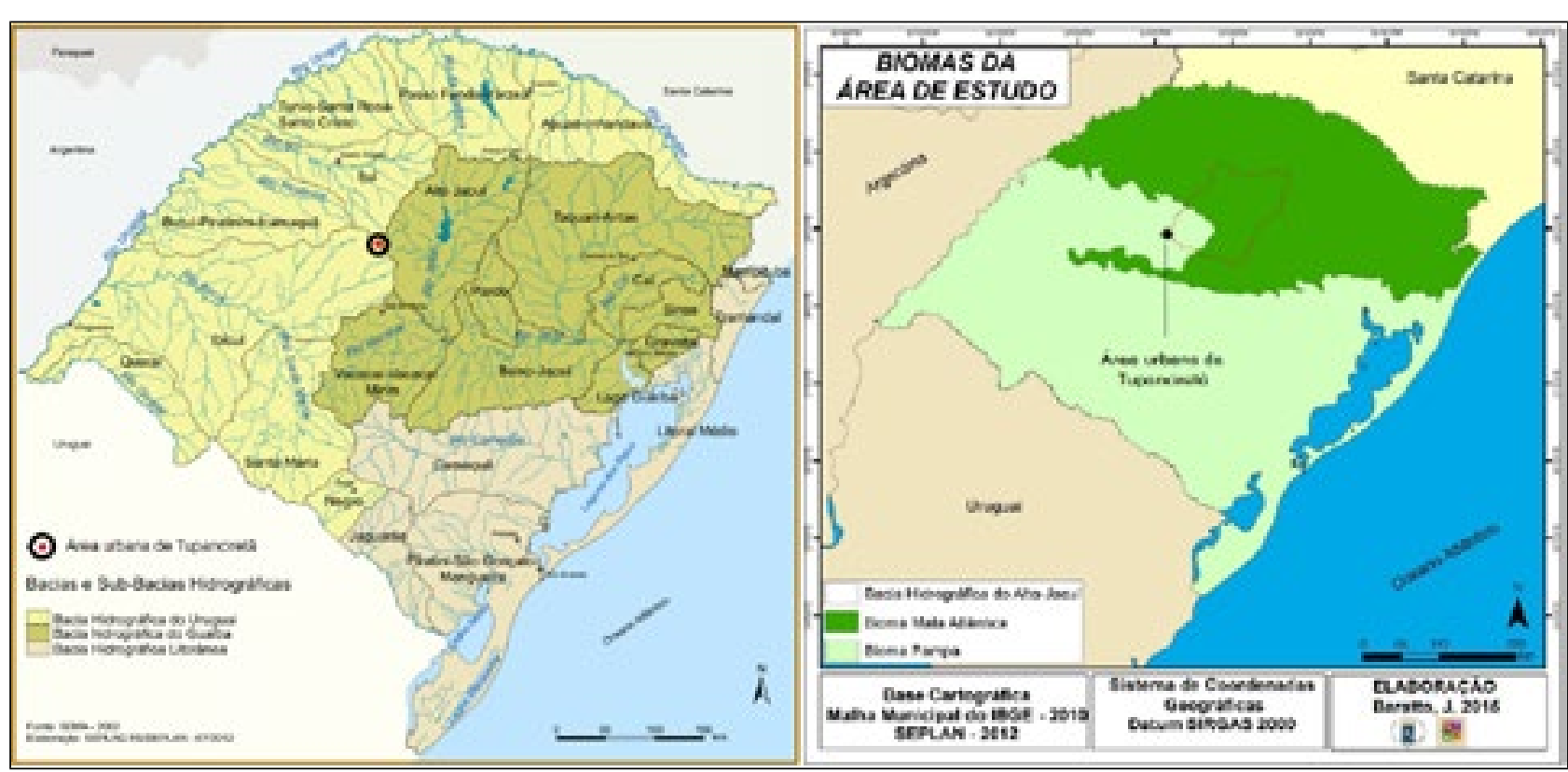

Figura 01 - Localização da área urbana de Tupanciretã nos contextos hidrográficos e biogeográficos.

Devido ao fato de ser a capital da soja, a área urbana de Tupanciretã concentra um comércio de porte expressivo para uma cidade com pouco mais de vinte mil habitantes. O setor de comércios diversos e serviços que atendem os produtores rurais do município e cidades menores vizinhas são o que mais atraem pessoas, movimento e circulação e automóveis e caminhões na área urbana, sendo estes, portanto, fatos que podem contribuir para o aquecimento antrópico desta cidade.

\section{Materiais e Procedimentos Metodológicos}

3.1 Dos instrumentos utilizados e preparação para os trabalhos de campo (transectos móveis)

Para realizar este trabalho referente ao estudo do campo térmico de Tupanciretã/RS, utilizou-se de alguns procedimentos metodológicos a seguir discriminados. A proposição metodológica adotada nesta pesquisa segue a já consagrada Teoria do Sistema Clima Urbano (SCU) de Monteiro (1976), que é um referencial teórico-metodológico da Geografia, amplamente utilizado nas pesquisas do clima urbano das cidades brasileiras.

Para a aquisição dos dados de temperatura do ar na zona urbana de Tupanciretã, foi empregada a metodologia dos transectos móveis, a qual consiste na aquisição automática e simultânea de dados climáticos ao longo do trajeto dentro da malha urbana. Para tal foram estabelecidos dois transectos cortando a cidade de Tupanciretã nos sentidos leste-oeste e norte-sul (Figura 03)

A realização do transecto ocorreu no horário das 15 horas, com condições de tempo estável, céu limpo e pouco vento (calmaria). O trabalho de campo foi realizado no dia 01 de abril de 2016, em condições meteorológicas favoráveis para a coleta dos dados. Para a aquisição dos dados foram utilizados dois termo-higrômetros, com registradores digitais, modelo HT 500 Instrutherm. Tais registradores são pré-programáveis e automáticos. Os aparelhos foram programados para realizar a aquisição automática dos valores de temperatura e umidade relativa do ar a cada 10 segundos à medida que serão realizados os transectos, com utilização de automóvel, a uma velocidade média de deslocamento entre 20 e $30 \mathrm{~km} / \mathrm{h}$

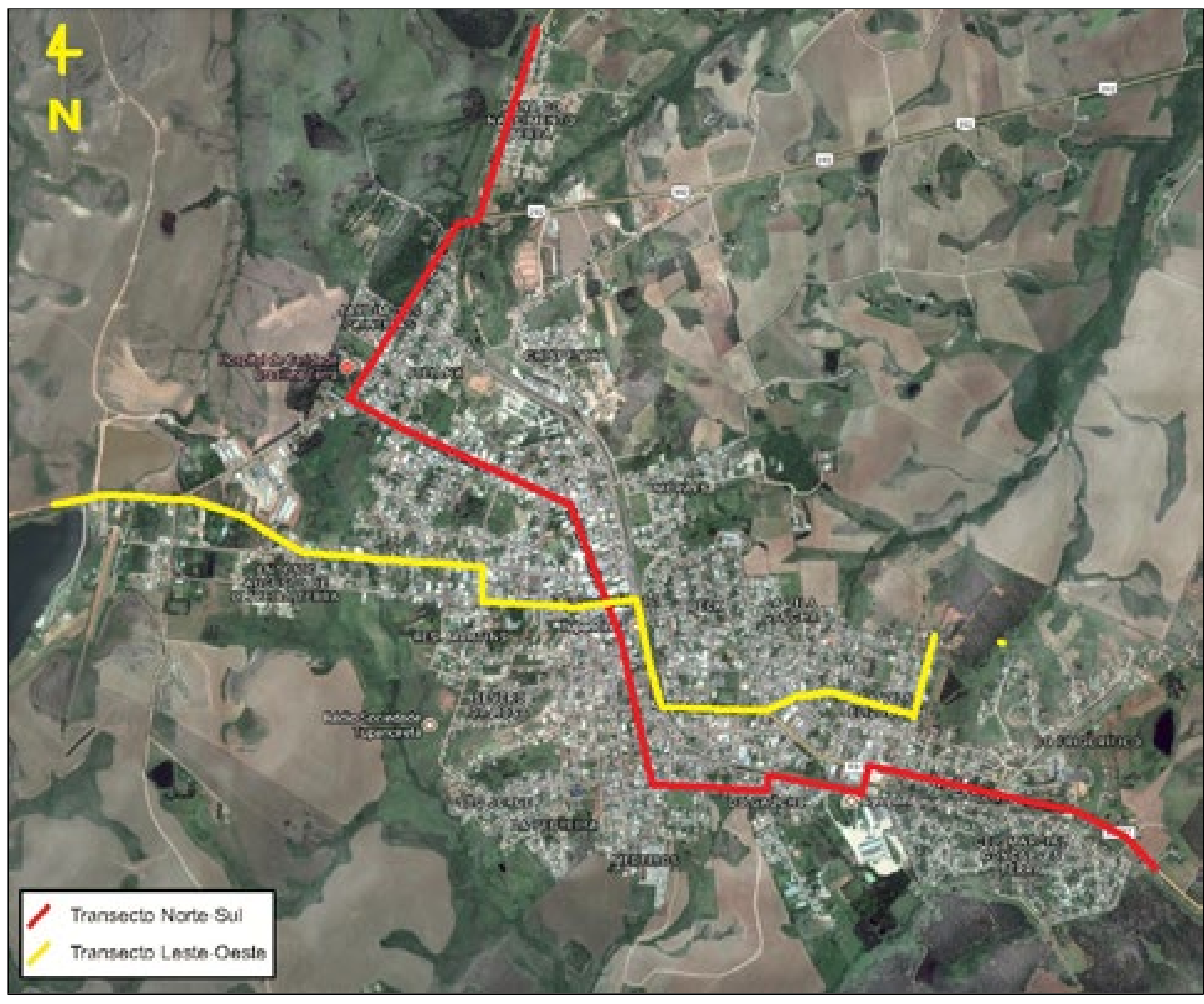

Figura 03 - Transectos móveis realizados na área urbana de Tupanciretã - RS.

Org.: Os autores (2017).

Para a aquisição dos dados ao longo dos transectos foram utilizados dois automóveis particulares, e cada um fez um trajeto (transecto), tendo o mesmo horário de início. Sendo necessários dois integrantes em cada carro: um condutor e um para o manuseio dos equipamentos.

A velocidade padrão dos automóveis ao percorrem os transectos nos horários de aquisição dos dados foi, em média, de 20 a $30 \mathrm{~km} / \mathrm{h}$ a fim de evitar a influência do vento nos registros feitos pelos aparelhos. O tempo percorrido pelos automóveis em cada transecto não ultrapassou 30 minutos, a fim de evitar uma maior discrepância dos dados entre o início e o final de cada trajeto.

Em cada automóvel, na lateral do veículo próximo a porta onde no interior da mesma foi inserido o aparelho (Figura 04), juntamente com uma estrutura em ferro galvanizado pintado com tinta branca, que é um miniabrigo meteorológico, para que o datalloger não fique em contato direto com o vento provocado pelo deslocamento do carro, com a finalidade de não serem produzidas distorções nos registros em campo. 

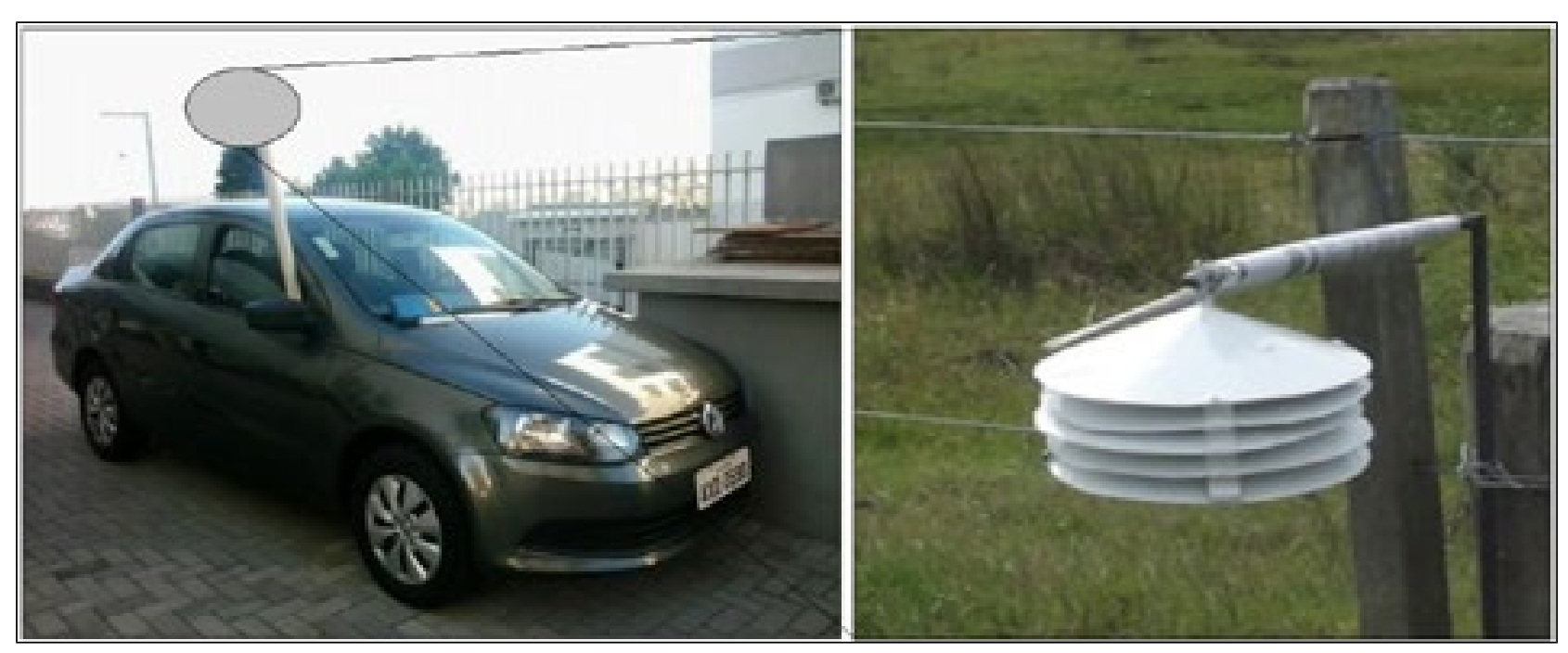

Figura 04 - Um dos automóveis utilizados para a aquisição dos dados de temperatura do ar na zona urbana de Tupanciretã/RS, e estrutura em ferro galvanizado pintada de branco próximo à porta do veículo, onde foi colocado o instrumento.

Tanto os termômetros quanto os miniabrigos meteorológicos são materiais de pesquisa pertencentes ao Laboratório de Climatologia Geográfica, do Departamento de Geociências da Universidade Federal de Santa Maria, e sua eficiência já foi testada em trabalhos anteriores, conforme salientaram Wollmann e Simioni (2013) e Hoppe; et. al. (2015).

Foram coletadas 14 amostras em cada transecto, totalizando 28 coletas de temperatura do ar. Houve ainda a utilização também de dois localizadores GPS de navegação, um em cada carro, (marca Garmin modelo 400), para a aquisição de coordenadas planas do Sistema UTM (Universal Transversa de Mercator) ao longo dos transectos. Estes instrumentos pertencem ao Departamento de Geociências.

\subsection{Do mapeamento da temperatura em Tupanciretã/RS}

Após a aquisição dos dados climáticos (temperatura e umidade relativa) e das coordenadas UTM, em campo, e no horário pré-estabelecido das 15 horas, os mesmos foram selecionados e tabulados em planilhas do Microsoft Excel 2010 a fim de serem utilizados no aplicativo Surfer 8.0 para a elaboração de cartogramas do campo térmico da zona urbana de Tupanciretã/RS. O método de interpolação utilizado na elaboração dos cartogramas foi a krigagem ordinária do Surfer, conforme orientam Wollmann e Galvani (2014).

Na elaboração do cartograma do campo térmico da zona urbana de Tupanciretã, ao longo dos transectos, houve o uso de escalas de cores que variaram do verde claro para representar temperaturas mais baixas até o vermelho escuro para temperaturas mais elevadas. O mapa que espacializa os dados térmicos dos transectos realizados em Tupanciretã, e ao final, procurou-se estabelecer a relação destas com a presença de elementos geourbanos e geoecológicos da área de estudo.

3.3 Da análise sinótica nos dias de levantamento do sistema termodinâmico
Houve a coleta de dados diários dos elementos climáticos, especialmente de temperatura do ar, umidade relativa do ar, pressão atmosférica e direção do vento da Estação Meteorológica de Cruz Alta/RS, a mais próxima da área de estudo $(50 \mathrm{~km})$, para serem analisados e comparados com os dados coletados em Tupanciretã no episódio de levantamento dos transectos móveis (junho de 2013).

Com o intuito de se determinar o tipo de tempo, os sistemas atmosféricos dominantes e a circulação atmosférica regional no dia de aquisição dos dados foram utilizadas imagens de satélite GOES-13 e cartas sinóticas de superfície, ambas disponíveis nas páginas do CPTEC/INPE (www.cptec.inpe.br) e Marinha do Brasil (www.mar.mil.br/dhn/chm/meteo/prev/cartas/cartas).

\section{Resultados e Discussões}

4.1. Variabilidade dos atributos do clima e identificação dos sistemas atmosféricos em Tupanciretã/RS

Após coleta dos dados em campo, foi feita coleta, no dia seguinte (02/04/2016) dos dados oficiais da Estação Meteorológica de Cruz Alta, pertencente à Rede do Instituto Nacional de Meteorologia (INMET). Segundo os dados oficiais, a temperatura média do ar para este dia estava em $26,8^{\circ} \mathrm{C}$, umidade relativa de $86 \%$ e sem registro de precipitação. Vento com direção predominante de norte e velocidade média $2 \mathrm{~m} / \mathrm{s}$. Nebulosidade em 4 décimos.

Para a identificação dos sistemas atmosféricos, foram utilizadas as cartas sinóticas e imagens de satélite da 00h, 12h e 15h, conforme horários oficiais da Marinha do Brasil para confecção das cartas isobáricas, que podem ser melhor visualizadas na Figura 05 . 


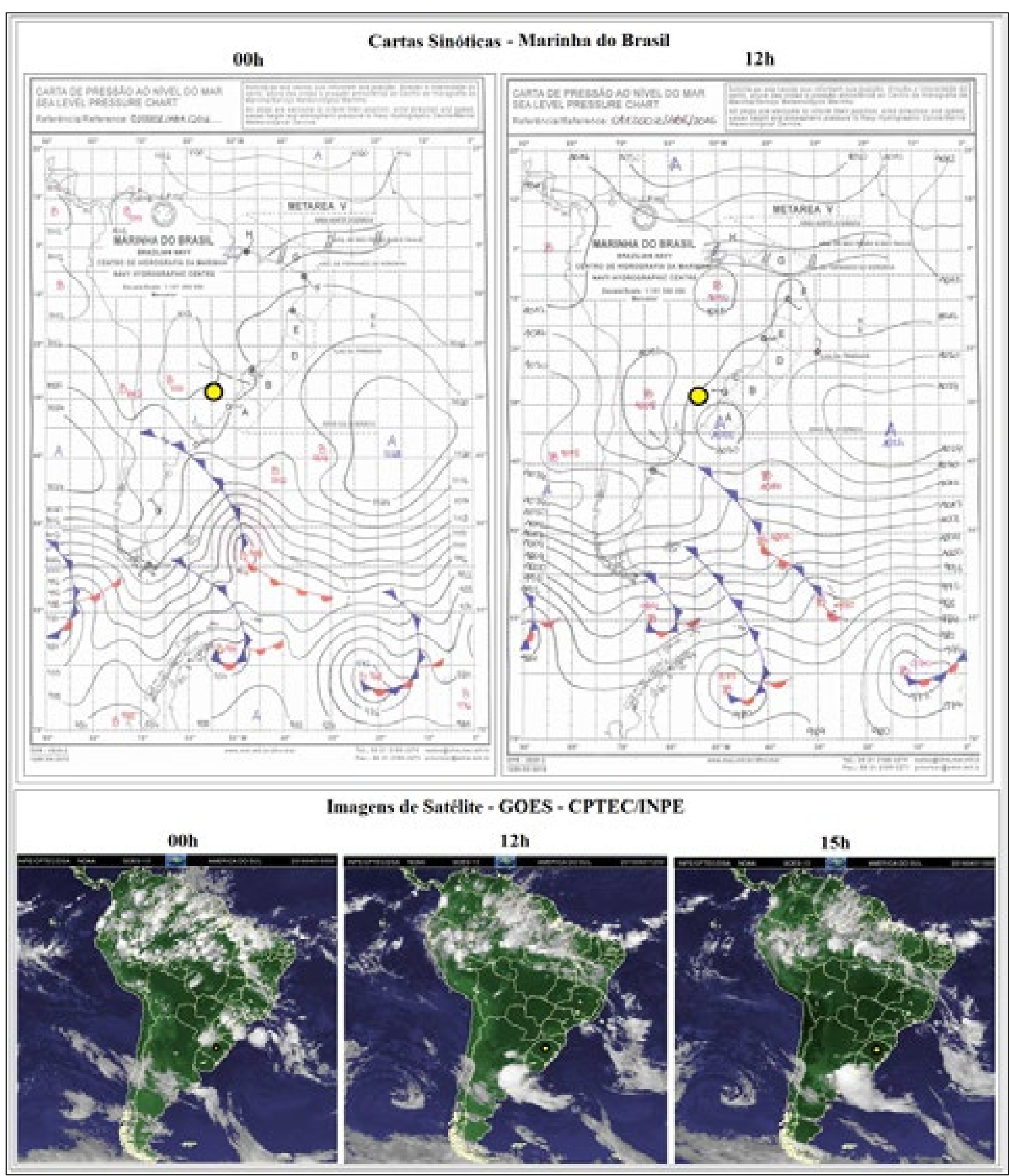

Figura 05 - Cartas Sinóticas e Imagens de Satélite do dia 01/04/2016, com destaque para a localização de Tupanciretã/RS (bolinha amarela). Fonte: Cartas Sinóticas da Marinha do Brasil / Imagens de Satélite CPTEC/INPE. Org.: Os autores.

De acordo com a Figura 05, observa-se que o Estado do Rio Grande do Sul, e consequentemente Tupanciretã, no período das $00 \mathrm{~h}$ estavam sob domínio do avanço da Baixa do Chaco e consequentemente sua Massa Tropical Continental - MTC, cujo domínio perdeu força a partir da carta e imagem das $12 \mathrm{~h}$, pois na imagem referente às 00h, dando lugar a uma subdivisão do Anticiclone Tropical Atlântico e sua Massa Tropical Attântica - MTA. Havia ainda o eixo da Frente Polar Atlântica (FPA) encontrava-se na divisa com Uruguai, colocando o estado do Rio Grande do Sul em situação pré-frontal.

Esta situação sinótica apresenta o centro isobárico sobre as latitudes de $35^{\circ} \mathrm{S}$ sobre o continente (trajetória continental) registrando-se $1024 \mathrm{mb}$. Cruzando-se com os dados da Estação Meteorológica de Cruz Alta, a direção predominante do vento neste dia era do quadrante Norte $(\mathrm{N})$, principalmente no período após as $12 \mathrm{~h}$. A presença do Anticiclone Tropical Atlântico é evidenciada por ter elevado as temperaturas na parte da tarde, bem como ser registrada elevada umidade relativa do ar (85\%), e a situação sinótica apresentar a nebulosidade de 4 décimos, já oriunda da aproximação da nova frente fria.

Quanto à fase de domínio, segundo Sartori (2003, p. 38), evidencia-se a fase de domínio transicional, na qual a autora coloca que:

Essa situação provoca um tipo de tempo caracterizado por ventos leves de $\mathrm{E}$ - NE, devido à circulação anticiclonal, calmas, ceu limpo, que favorece elevação das temperaturas máxima e minima, com grandes amplitudes térmicas, formação de orvalho e declínio da umidade relativa [...] Embora essa sucessão de tipos de tempo seja a mais habitual no Rio Grande do Su ao longo do ano, algumas situaçôes de tempo afetam o conforto e bem-estar da população, provocando reaçōes psicofisiologicas que, por sua vez, dependem da temposensitividade de cada individuo. Essas situações são episodios de duração variavel, em que as mesmas condições permanecem vento Minuano e Vento Norte.

Nesse sentido, os dados coletados em campo e na Estação meteorológica de Cruz Alta, com temperatura entre $24^{\circ} \mathrm{C}$ e $32^{\circ} \mathrm{C}$ (e amplitude de aproximadamente de $12^{\circ} \mathrm{C}$ ), umidade relativa do ar entre $68 \%$ e $100 \%$, e pressão atmosférica pouco abaixo dos valores de referência $(1013 \mathrm{mb})$ são as características comuns do Tempo Anticiclônico Tropical Atlântico (SARTORI, 2003), na parte da tarde, quando foi realizado o transecto móvel.

De acordo com Sartori (op. cit., p. 33-34) pode-se classificar este quadro sinótico e os tipos de tempo dessa data como de Tempo Depressionário Continental na parte da madrugada e manhã, e Tempo Anticiclônico Tropical Atlântico na parte da tarde. Segundo a autora, esses domínios atmosféricos podem ser caracterizados como

Tempo Depressionário Continental - Resulta da expansão da Massa Tropical Continental, devido ao aprofundamento da Depressão do Chaco, que eventualmente atinge o Rio Grande do Sul. Esse tipo de tempo é do mais característicos, pois as temperaturas máximas são quase sempre superiores a $35^{\circ} \mathrm{C}$, com pressão atmosférica muito baixa (inferiores à̀ demais situações pré-frontais sob domínio da MPV, da MTA ou da MTAc), baixa umidade relativa pela origem continental da massa de ar e pela forte insolação, ventos do quadrante oeste (W e NW) de intensidade variável. Tempo Anticiclônico Tropical Marítimo - Relacionado ao domínio na nordeste (NE) que origina tempo bom, com fluxos predominantemente de

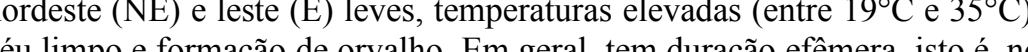
céu limpo e formação de orvalho. Em geral, tem duração efemera, isto e, no a MPV na fase pré-frontal, quando se dá a fusão do Anticiclone Polar com ATA. 
4.2. Variação espacial da temperatura na área urbana de Tupanciretã/RS

Consoante à metodologia proposta para esta pesquisa, realizou-se o mapeamento da variabilidade espacial da temperatura do ar na área urbana de Tupanciretã a fim de que se possa observar se houve relação entre a mesma e os diferentes ambientes urbanos. Nesse sentido, a Figura 06 apresenta a variabilidade espacial da temperatura média do ar registrada às $15 \mathrm{~h}$ conforme levantamento feito pelos transectos.

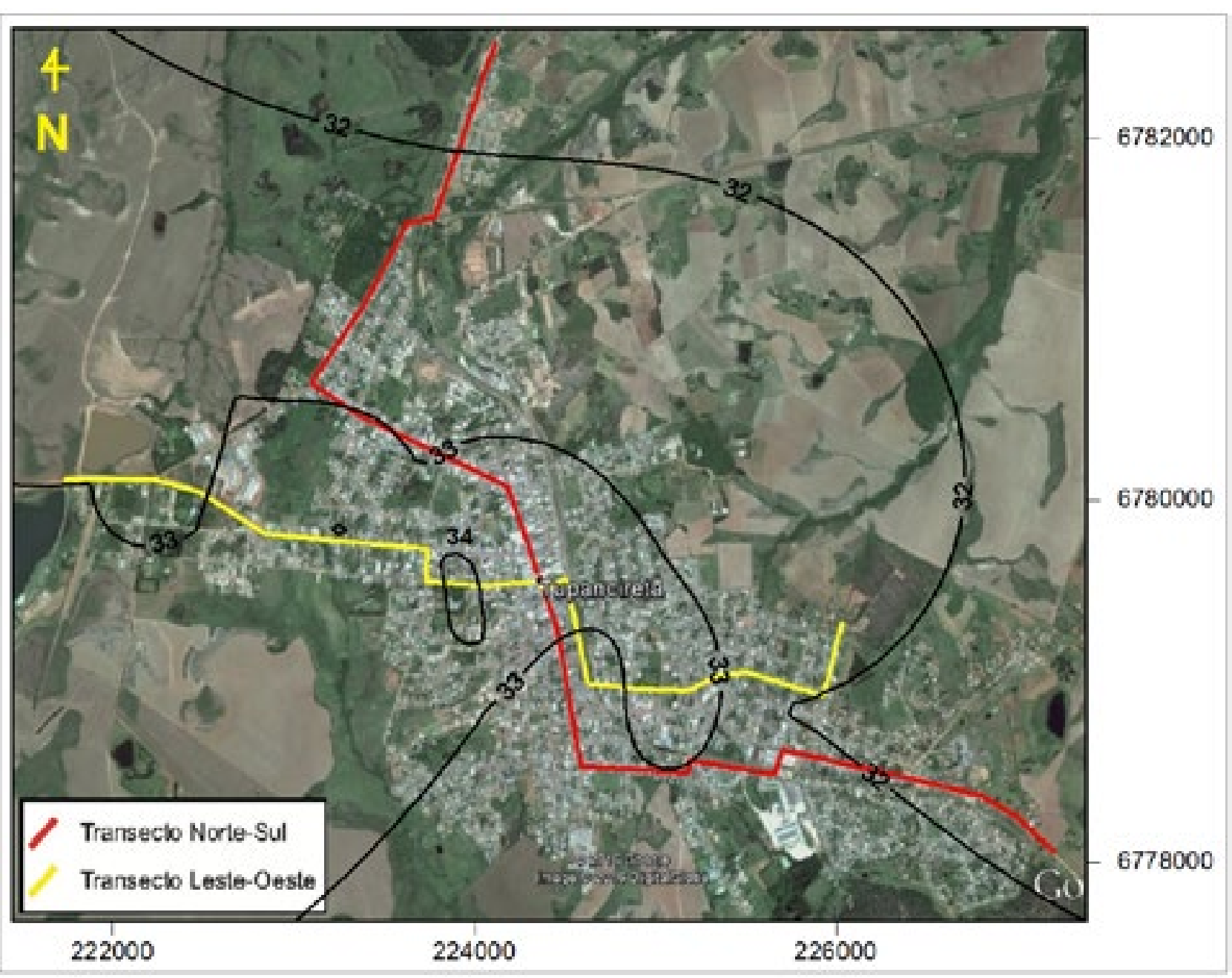

Figura 06 - Variabilidade espacial da temperatura média do ar na área urbana de Tupanciretã/RS, às 15h, de 01 de abril de 2016.

Org.: Os autores (2017).

De acordo com a Figura 06, analisando-se a temperatura do ar às $15 \mathrm{~h}$ na área urbana, observou-se que a cidade de Tupanciretã sofre uma influência de média magnitude dos seus componentes urbanos. A disposição das edificações e a distribuição das áreas verdes também acabam por influenciar nas temperaturas da cidade.

As maiores temperaturas foram constatadas no centro da cidade e nos bairros próximos, especialmente à oeste do Centro. Apesar da presença de áreas verdes, as fábricas e indústrias, ao norte do centro da cidade, acabam por influenciar no aumento das temperaturas, a emissão de gases poluentes e a presença de construções voltadas para a acomodação das indústrias acabam por ocasionar a constatação de temperaturas mais elevadas.
Em comparação com os dados registrados na Estação Meteorológica de Cruz Alta, esta área da cidade foi a que apresentou maior magnitude, com temperaturas cerca de $6^{\circ} \mathrm{C}$ acima do registrado no dado oficial $\left(28,6^{\circ} \mathrm{C}\right.$ na estação oficial do INMET)

O centro da cidade e seu entorno próximo é outro ponto que se encontram temperaturas mais elevadas com relação ao restante da cidade, por volta de $33^{\circ} \mathrm{C}$, enquanto que os arredores rurais registraram $32^{\circ} \mathrm{C}$ (fraca magnitude). Fatores como maior concentração populacional, maior deslocamento de veículos, por consequência a emissão de gases e a suspensão de partículas e maior concentração de edificações ocasionam temperaturas elevadas. A orientação das vertentes na região central do município também acabam por influenciar nas temperaturas, onde a incisão dos raios solares é maior nas vertentes com orientação oeste e norte.

Como a medição foi realizada no horário das $15 \mathrm{~h}$ o Sol estava voltado para estas vertentes, havendo assim um maior aquecimento desta, aumentando ainda mais o calor em comparação (cerca de $5^{\circ} \mathrm{C}$ ) com os dados registrados na Estação Meteorológica de Cruz Alta.

Já nos bairros localizados no extremo norte e sudeste da cidade, as temperaturas registradas foram registradas em torno de $32^{\circ} \mathrm{C}$ (mas mesmo assim cerca de 3 a $4^{\circ} \mathrm{C}$ maiores que o registrado na estação meteorológica) por apresentarem maior número de casas residenciais e áreas verdes, onde a altura das edificações e os espaços que há entre elas devido ao espaçamento da construção facilita a circulação dos ventos. Ainda, a presença de áreas verdes amenizam o calor, por apresentarem maior conservação da umidade e absorção do calor. A circulação de pessoas e de veículos, por serem bairros majoritariamente residenciais, é muito menor se relacionados com outros locais da cidade, como o Centro, ocasionando as menores temperaturas constatadas na área urbana de Tupanciretã. Outro ponto importante a ser observado é que nestes bairros da cidade, a orientação das vertentes é predominantemente de leste e sul, ocasionando menor incidência direta da radiação solar, contribuindo para um menor aquecimento nestes bairros. A presença de arroios e banhados nestes bairros auxiliam na redução das temperaturas quando comparado com o Centro da cidade

Ainda, as áreas rurais localizadas a norte e leste da área urbana, cujas vertentes estão voltadas para o leste, estando com menos radiação incidente no período da tarde. Tal fato comprova o amortecimento que áreas verdes (mesmo sendo de usos rurais) possuem sobre as temperaturas do ar registradas nos centros urbanos, para tal, sua implantação torna-se de suma importância para aumento da qualidade ambiental nas cidades.

\section{Considerações Finais}

Neste trabalho pretendeu-se estudar de forma inicial e preliminar o ambiente urbano de Tupanciretã/RS e sua relação com um atributo do clima, tido pela literatura científica como a mais alterada por este ambiente: a temperatura do ar. A partir do referencial teórico abordado, dos dados coletados em campo (primários e secundários) e sua posterior análise, considerou-se alguns pressupostos observados e que impõem resultados à pesquisa.

Observou-se que a área urbana de Tupanciretã, ainda que este município seja pequeno, já causa uma influência de média magnitude $\left(2^{\circ} \mathrm{C}\right)$ na variação espacial da temperatura em seu sítio urbano, e de até $6^{\circ} \mathrm{C}$ em comparação com os dados oficiais da estação meteorológica. Evidenciou-se também a relação das diferenças térmicas registradas entre o rural e o espaço urbano de Tupanciretã, as quais promoveram, em alguns locais, redução de até $50 \%$ das temperaturas registradas nos locais mais quentes. 
Salienta-se que esta variação térmica é resposta ao domínio de sistemas atmosféricos tropicais, e que tais variações térmicas podem ocorrer com maior, ou menor, intensidade/magnitude dependendo dos tipos de sistemas atmosféricos e tipos de tempos inerentes em função da sequencia habitual dos tipos de tempo no Rio Grande do Sul, e consequentemente em Tupanciretã. Para evidenciar tais fatos, salienta-se e realização de novas pesquisas neste ambiente urbano.

Com isso, acredita-se que este trabalho possa servir de base e motivar pesquisas futuras de clima urbano voltadas à cidade de Tupanciretã/RS, dado ao seu ineditismo, e tais pesquisas serem incorporadas no planejamento climático urbano do município, uma vez que as cidades médias de todo o Brasil, bem como do Rio Grande do Sul, carecem de tais estudos.

\section{Agradecimentos}

O presente trabalho foi realizado com apoio do Programa Nacional de Cooperação Acadêmica da Coordenação de Aperfeiçoamento de Pessoal de Nível Superior - CAPES/Brasil - $\mathrm{N}^{\mathrm{o}}$ Processo: 88881.068465/2014/01 no 071/2013 CAPES/PROCAD.

\section{Referências}

BARATTO, J. Variabilidade da precipitação pluviométrica na bacia hidrográfica do Alto Jacuí - RS. Dissertação (mestrado em Geografia). Universidade Federal de Santa Maria. 2017. 177p.

HOPPE, I. L.; IENSSE, A. C.; SIMIONI, J. P. D.; WOLLMANN, C. A. Comparação entre um abrigo meteorológico de baixo custo e a estação meteorológica oficial no INMET, em Santa Maria (RS). Ciência \& Natura, v. 37, p. 132-137, 2015.

INSTITUTO BRASILEIRO DE GEOGRAFIA E ESTATÍSTICA, Dados Demográficos $2010 . \quad$ IBGE, 2014. Disponível em <www.ibge.gov.br>. Acesso em 13 jul. 2017.

MENDONÇA, F. A. O Clima e o planejamento urbano de cidades de porte médio e pequeno: proposição metodológica para estudo e sua aplicação à cidade de Londrina - PR. 1994. 322f. Tese (Doutorado em Geografia)Universidade de São Paulo, São Paulo, 1994.

MONTEIRO, C. A. F. Teoria e Clima Urbano. Série Teses e Monografias, $\mathrm{n}^{\mathrm{o}}$ 25. São Paulo: Instituto de Geografia/USP, 1976.181p.

SANTOS, M. A Urbanização Brasileira. São Paulo: EDUSP, 1993.

SARTORI, M. G. B. A dinâmica do clima do Rio Grande do Sul: indução empírica e conhecimento científico. Revista Terra Livre, São Paulo, v. 1, n. 20, p. 27-49, jan./jul. 2003.

SECRETARIA ESTADUAL DE PLANEJAMENTO E DESENVOLVIMENTO REGIONAL - SEPLAN. Atlas Socioambiental do Rio Grande do Sul. Porto Alegre: SEPLAN/RS. 2006. Disponível em: $<$ http://www.atlassocioeconomico.rs.gov.br>. Acesso em: 21 de março de 2017.

WOLlMANN, C. A.; GALVANI, E. Zoneamento Agroclimático - Aportes teóricos, metodológicos e técnicas para o estudo das roseiras (Rosaceae spp.) no Rio Grande do Sul. 1. Ed. Porto Alegre: Buqui Livros digitais, 2014. V. 1. $149 \mathrm{p}$.

WOLLMANN, C. A; SIMIONI, J. P. D. Variabilidade espacial dos atributos climáticos na Estação Ecológica do Taim (RS), sob domínio polar. Revista do Departamento de Geografia - USP, Volume 25, p. 56-76. 2013. 